attendant upon such works fall less heavily upon those who undertake their compilation, and a fair number of subscribers is more readily obtained. Although much has already been done in publishing such works, there is still much remaining to be done; we could wish, for example, that the Manchester naturalists would publish a new and more complete edition of the "Manchester Flora," and that the Liverpool people would issue in a separate and completed form the flora which appeared in part in their journal. These floras, with that of Birmingham, if carefully worked out, with full references to the older writers, would be of a value second only to that of Trimen and Dyer's "Flora of Middlesex," as showing the influence of cultivation upon the botany of a district.

We must not dismiss the subject of publications without a reference to one or two of those emanating from more recently established societies, which have been favourably received. The Woolhope Club has now issued four volumes, copiously illustrated with photographs and coloured lithographs, the contents of which are of somewhat more general interest than those we have already referred to. This being the case, we can but regret that the volumes are inaccessible to the general public; but a limited number only are printed, which are almost confined in circulation to the members of the club. Noteworthy papers are those on the remarkable trees of Herefordshire (adorned with some exquisite photographs), on the fungi of the county, and on its geology ; while the antiquarian will find some prominence given to archæology. The Malvern Naturalists' transactions are similar in general features to those of the Woolhope Club, and we observe that the two societies vie with each other in the attention they bestow upon edible fungi. The Birmingham Society has just issued the first volume of its proceedings-a very creditable one-which has the additional advantage of being obtainable by outsiders at the moderate cost of half-a-crown. We need not remark further upon this, as a notice of it lately appeared in our columns.

The general arrangement of meetings, \&c., must depend almost entirely upon local circumstances; and the same remark will apply to rules, which should be as few and simple as possible. As we are now speaking only of firmly established bodies, any hints upon these matters are deferred for a second paper.

\section{A WORD ABOUT YALE}

T $\mathrm{HE}$ following account of the Yale University scheme, by Professor J. D. Dana, is taken from the Yale College Conrant:-

I. The Classical or Academic and the Scientific departments (ordinarily called Yale College, and the Sheffield School of Science) are distinct colleges for the undergraduate students of the University-distinct in teachers, scholars, buildings, apparatus, and special working libraries. They have in common a general library, and the officers meet for the discussion of University questions in a common University Faculty.

2. In each college the first two years of the four* are years of preparatory study without optional or elective courses, except perhaps in place of the higher mathema-

* The three-years' course of the Scientific School will probably be made four-years' course within a year or two. tics of the second year. After the close of the second year a number of elective courses are before the student.

3. In the Academic College-whose special subjects of study are the classics, modern languages, mathematics, astronomy, history, intellectual and moral philosophy, political economy, general literature, \&c.- the principles of natural science, physics, and chemistry are taught so far as is necessary to give depth and breadth to an academic education; a general knowledge of the laws or systems of nature, both organic and inorganic, being essential in these days to a true scholar, whatever his purpose in life.

4. In the Scientific College-whose special subjects of study are the various natural sciences, physics, chemistry, mathematics, and the practical applications of these sciences-literary subjects are added, including modern languages (some knowledge of the ancient languages being required for entering), political, moral, and intellectual science, history, physical and political geography, \&c.in order to give in this branch of the University a thorough and well-grounded education, and make the graduate a man of high culture.

5. In the Academic College, optional or elective courses are confined to its special subjects of study: ( $\mathrm{I}$ ) the classics, (2) modern languages, (3) English language and Jiterature, (4) mathematics. None are allowed in the departments of natural, chemical, or physical science, as these subjects are admitted into this college only so far as is necessary to give that breadth and depth to education which every graduate should have.

6. In the Scientific College also, elective courses are confined to its special objects of study-that is, to the natural sciences, physics, geology, metallurgy, mechanics, engineering, \&c.

7. The post-graduate courses of the University comprise many distinct departments in the lines of the Academic and Scientific Colleges. Connected with the former, there are (or may be) courses in Latin, Greek, different Oriental languages, linguistics, English language and literature, history, intellectual philosophy, mathematics, astronomy, \&c. \&c. Connected with the latter there are (or may be): First, in pure science, courses severally in the different physical sciences, general chemistry, organic chemistry, mineralogy, botany, zoology, palæeontology, geology, mathematics, astronomy, \&c.; Secondly, in applied science, courses in civil engineering, mechanical engineering, mining and mining engineering, practical mechanics, metallurgy, agriculture and agricultural chemistry, \&c.

8. The students of the Academic College take, on graduating, the clegree of Bachelor of Arts; and those of the Scientific College that of Bachelor of Philosophy.

The students of the post-graduate courses, after two years of study, in which high scholarship is attained as tested by a rigid examination, take the degree of Doctor of Philosophy; except in the case of students in Civil Engineering, who may receive that of Civil Engineer after one year of study.

The University includes also the Schools of Law, Medicine, Theology, and the Fine Arts. But of these it is not necessary here to speak. Neither of them has, in any part of its curriculum, an undergraduate department analogous to that of the Academic or Scientific Coliege. 
In connection with the above brief statement I offer the following remarks :-

I. The ranges of studies in the two colleges, the Academic and Scientific, are so diverse in character, that the interests of the students and of education are better subserved by two distinct faculties working separately, than by onc single combined faculty. There is not in the Yale scheme that multiplicity of optionals before the students after they have entered the University, which inconveniently subdivides classes, offers inducements to indolence, and tends to break down thorough discipline and study; for, in the act of entering, the student decides as to the range of his optionals; and if afterwards not satisfied (which would seldom be the case) he can join the other college.

2. It might be supposed that the scheme would require an unnecessary duplication of professors. But this is not so at Yale. In the Academic College there are already four instructors in Greek, four in Latin, five in mathematics, physics, and astronomy ; and the professors of rhetoric, history, moral and intellectual philosophy, \&c., are more than well occupied with their academic labours. The scientific students, if embraced in the Academic College, would actually require as many additional instructors as are needed under the existing system of the University.

3. In some scientific departments in the Academic College (zoology and botany, for example), in which the instruction occupies but a small part of the college course, there is no objection to employing the services of some of the scientific faculty, if this is feasible; and, where possible, the academic faculty may serve the Scientific College. Moreover, while all lecture-rooms had better be separate, the more costly kinds of apparatus may well be used in common, in order to avojd needless expenditure.

4. It may be added that many scientific students commence their training as scholars by first graduating in the Academic College. For the higher training in science, such a preparatory course in the classics is believed to be eminently desirable. They then enter an advanced slass in some one of the departments in the Scientific College, and take the degree of Bachelor of Philosophy, or of Civil Engineer ; or by special proficiency, after two rears of study, that of Doctor of Philosophy. The Scientific College also admits of partial courses of study which do not lead to any degree.

5. The modification in American colleges which is Jemanded by the vast development of the sciences of zature within the past century - the era of origination for nany of them-and also by the contemporary progress of inguistic and other sciences, is accomplished by the Yale scheme through a method which does not sacrifice, $\mathrm{n}$ any degree, classical education, and which at the same ime combines thorough literary culture with the widest ange and highest development of scientific education. The Classical College stands beside the Scientific, open 0 all who desire to commence with a classical basis; and he Scientific College offers a thorough and liberal eduation for all who would pursue a more distinctively icientific course.

6. The Yale scheme contemplates no imporiant change $\mathrm{n}$ the Classical or Academic College except in the eleva. tion of the department of modern languages and literature; and its ideal with regard to modern languages cannot be wholly realised until a knowledge of French and German is given (like that of Latin and Greek) in preparatory schools, and required for admission to the college.

7. The great change that has taken place at Yale is in the introduction of its School of Science. This school is not the result of any precuncerted plan on the part of the University. It is a gradual growth of the past twenty years, urged on by the demand in the land for scientific knowledge among lovers of science, those seeking to become its teachers, and others interested in its practical departments; and it has been carried forward to its present organisation mainly through the labours and judgment of the scientific men who have been slowly gathered into its faculty. More than two-thirds of its endowments are duc to private munificence, and the remainder to the National Agricultural and Mechanical Fund.

\section{WALLACE ON NATURAL SELECTION}

Contributions to the Theory of Natural Selection. A Series of Essays. By Alfred Russel Wallace. (Londōn: Macmillan and Co., 1870 .)

$\mathrm{N}$ the discussions of the French Academy, to which 1 we referred in a recent number, $M$. Elie de Beaumont ventured to describe Mr. Darwin's theory as La Science Mousseuse. The phrase is a good one, and expresses very happily the kind of work for which some of the speakers in that debate are distinguished. But although we too in England are not unacquainted with this kind of popular science, scientific works do from time to time appear which are popular without being frothy, and to this class the present book belongs. While strictly accurate in matter, it is easy in style, and is so free from technical language, that it may be understood by educated men who are not professed naturalists; so that we hope it will be read by a large number of those to whom Mr. Wallace's delightful volumes have made the Malay Archipelago familiar.

The arrangement of the essays (most of which have been published separately) does not, perinaps, bring out their mutual connection so well as might be, and there is no attempt to blend them into a continuous series. Four main subjects are discussed, and each has its own peculiar interest.

The first and second chapters are reprinted as originally written in the East Indies, and, with the eighth, form Mr. Wailace's contribution to the theory of natural selection in general. It is remarkable that the same pregnant idea which Mr. Darwin has for ever united with his name should have occurred independently to another English naturalist on the other side of the globe. The public opinion of the scientific world will no doubt assign $\mathrm{Mr}$. Wallace the full credit which the preface to this volume so modestly claims; and the highest respect is due to his varied and fruitful labours in both hemispheres; but a warmer feeling than respect will be paid to the spirit by which the following passage was prompted:- "I have felt all my life, and I still fcel, the most sincere satisfaction that Mr. Darwin had been at work long before me, and that it was not left for me to attempt to write "The 